\title{
Under-Ventilated Compartment Fires: A Full-Scale Test with Wood Pallets
}

\author{
A. COPPALLE ${ }^{1}$, JEAN PIERRE GARO ${ }^{2}$, GAËTAN MITANCHEZ ${ }^{3}$, PAUL JOURDA $^{4}$, and \\ FRANCK GAVIOT-BLANC ${ }^{5}$ \\ ${ }^{1}$ UMR 6614 CORIA, France, \\ Campus du Madrillet, Av. de l'Université - BP 8 \\ 76801 Saint Etienne du Rouvray Cedex, France \\ ${ }^{2} \mathrm{P}$-PRIME \\ ENSMA, BP40109 \\ 86961 Futuroscope, France \\ ${ }^{3}$ Gimaex \\ 8, Rue Henri-Becquerel, BP 215 \\ 77292 Mitry-Mory Cedex, France \\ ${ }^{4}$ CEA/DPSN \\ 8, Route du Panorama \\ BP 6, 92265 Fontenay-aux-Roses, France \\ ${ }^{5} \mathrm{IFP}$ \\ Process Development and Engineering Division \\ BP 3 - 69390 Vernaison, France
}

\begin{abstract}
Under-ventilated enclosed fires are recognized to be important scenarios, which can bring important potential risks. These phenomena occur with different ventilation conditions (natural or mechanical), providing insufficient oxygen concentration and over production of unburnt gases in the fire zone. A fullscale test has been performed using wood pallet fire. The test rig is built with marine containers. The fire occurs in a room and the smoke spreads in two other compartments. The experimental set-up provides source mass loss rate, temperatures close to the fire and in the smoke flows. Fire growth and smoke spread are detailed and analyzed. It is shown that, after an ignition period, oxygen depletion is strong in the fire room and an under-ventilated combustion occurs, and the temperatures begin to increase continuously everywhere in the compartments and in the smoke plume at the exit. CFD modeling of the fire growth has been performed by specifying the kinetic of the heat release rate (HRR) or with a simplified pyrolysis mechanism with one step. The sequence of the events, which have been observed inside the compartments during the test, is well reproduced within the CFD results. However, the comparison between calculated and observed temperatures highlights the difficulties to calculate the accurate heat release rate (HRR), its kinetic of growth and the maximum value, when the fire is in the under-ventilated regime.
\end{abstract}

KEYWORDS: modeling, heat release rate, compartment fires, large-scale test, under-ventilated.

\section{NOMENCLATURE LISTING}

A pre-exponential factor, Arrhenius law (1/s)

$E \quad$ activation energy, Arrhenius law $(\mathrm{kJ} / \mathrm{kmol})$

GER global equivalence ratio

Hcomb net heat of combustion $(\mathrm{MJ} / \mathrm{kg})$

HRRmax maximum heat release rate for the main source or total (MW)

$m_{f} \quad$ fuel mass flux $(\mathrm{kg} / \mathrm{s})$

$m_{a} \quad$ air mass flux $(\mathrm{kg} / \mathrm{s})$

$T s f s-j i \quad$ temperature measured in the smoke filling space at level $i$ above ground and measured on the $j$ th thermocouple tree $(\mathrm{K})$

\section{INTRODUCTION}

The CFD codes are now often used for fire safety engineering and one needs to know the domain of application of these models. A lot of experimental tests are available to perform the necessary validations, 
as for example those presented in the technical note of the computer code Fire Dynamics Simulator (FDS) [1]. Also, an important effort has also been done for applications for fire safety in nuclear power plant [2]. In the simple case of fires in a unique room, full-scale tests carried out by Stekler et al. with burners and with different openings can be used [3], or to perform calculation on a more realistic scenario one can use the recent results of the full-scale test performed in Scotland [4]. Most of these tests correspond to wellventilated cases for which the heat release rate is mainly control by the amount of combustible available and there is no strong oxygen depletion in the fire zone. The under-ventilated cases are recognized to be scenarios that can lead high damage in buildings. They correspond to cases in which the ventilation provides too small amount of oxygen in the fire zone or in which there is an over-production of gas combustible due to incomplete combustion. Recent works [5-7] on such fires have shown strong differences in the fire behavior and in their growth compared to well-ventilated cases. A research program was devoted in France in 2008 to the comparative study of means and methods of firefighters faced to under-ventilated fires. Full-scale test has been performed using wood pallets. This is not a fire with real furniture as encountered in buildings. However, the wood material was chosen because it produces large quantities of smoke and combustion involves the pyrolysis process that occurs with furniture or, more generally, with solid materials in fire compartments.

The experimental test rig will be first described, then results of temperature, mass loss rate of the fire sources and smoke properties at the exit will presented and discussed. The calculations of the fire growth have been performed with FDS v5.5. The different methods used to calculate the heat release rate will be presented. Comparison with observed temperatures will be shown and discussed.

\section{EXPERIMENTAL FACILITIES}

\section{Test Rig}

Figure 1 shows an overview of the installation. Two combustion sources (primary and secondary) were put in the fire room. This one is connected to a smoke filling space composed of two rooms. The ceiling of the room downstairs and the ground of the room upstairs are removed which provide a unique space. The smoke flow goes outside through a small door $\left(2 \times 0.73 \mathrm{~m}^{2}\right)$ which is the only one opening during the test. Each room is a maritime container (width $=2.44 \mathrm{~m}$, length $=6.10 \mathrm{~m}$, height $=2.59 \mathrm{~m}$ ). Walls are made with corrugated steel sheet of $3 \mathrm{~mm}$ thickness.

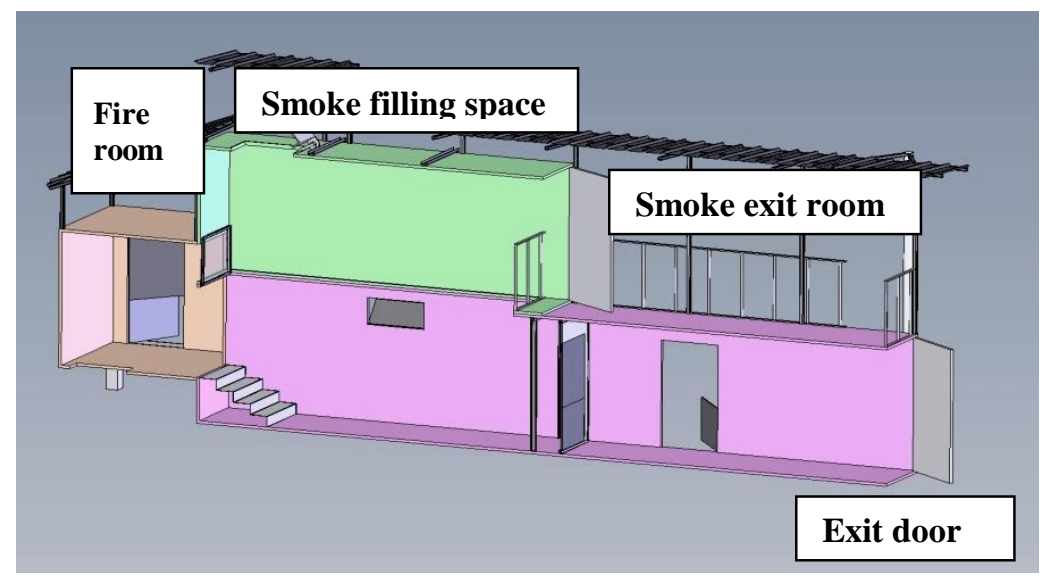

Fig. 1. Overview of the test rig using to study the under-ventilated fire.

Inside each room, walls and ceiling have insulated layers. The ground of the fire room is covered with heatresistant bricks put over a sand layer. There were two fuel sources in the fire room, they were made with wood pallets ( and the average relative humidity was found equal to $15 \%$. The first source was made up with a stack of 13 pallets (total weight: $264 \mathrm{~kg}$ ). The second one was made up with 3 pallets (total weight: $59 \mathrm{~kg}$ ), it was used as a target, because it was not ignited at the beginning. The main pallet stack was ignited with $400 \mathrm{ml}$ of 
heptane, the liquid being in a pan of $21.5 \mathrm{~cm}$ diameter and which was put inside the pallet stack close to the ground and on side. The fire spread to the target several minutes after ignition.

\section{Measurements}

An array of thermocouple probes was positioned inside the rooms as shown in Figs. 2 and 3. Thermocouples were put in the smoke filling space along the symmetry plane. So in the smoke filling space, temperatures are available at $i=9$ levels and $j=5$ vertical axis (quoted as $T s f s-j i$ in the remaining part of the paper).

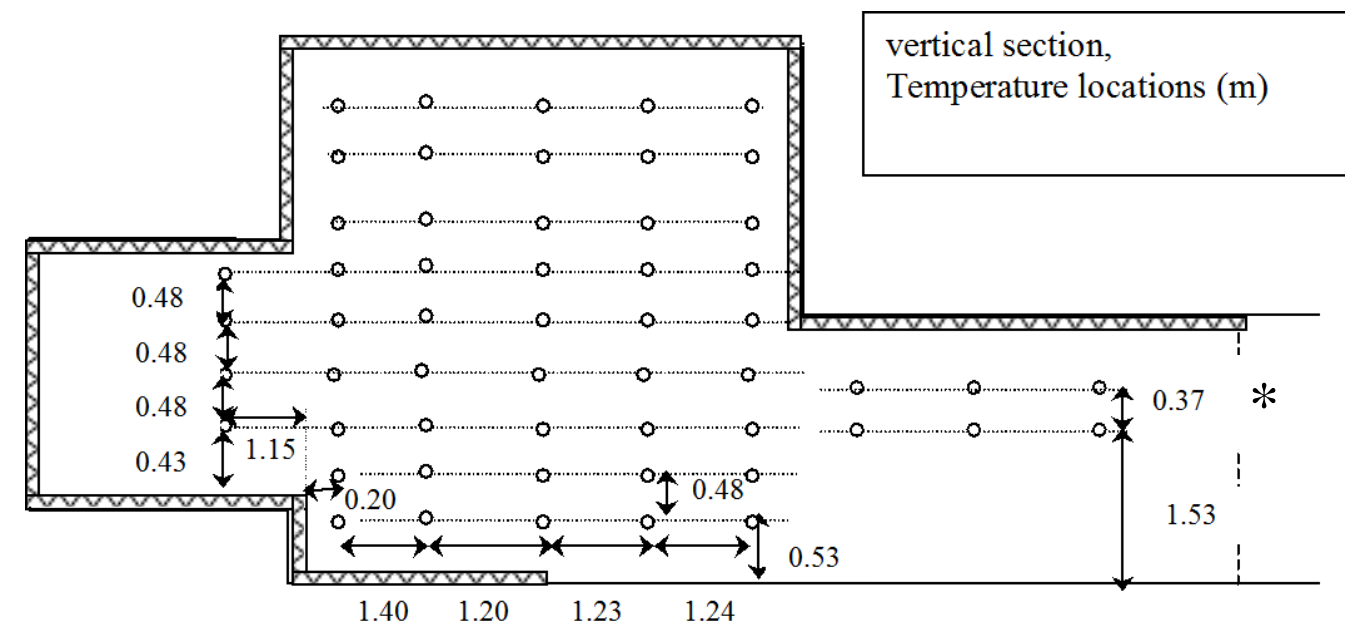

Fig. 2. Elevation view of the thermocouple locations, vertical section (distances in $\mathrm{m}$ ).

The mark * indicates the location of $\mathrm{O}_{2}$ probe at the exit door.

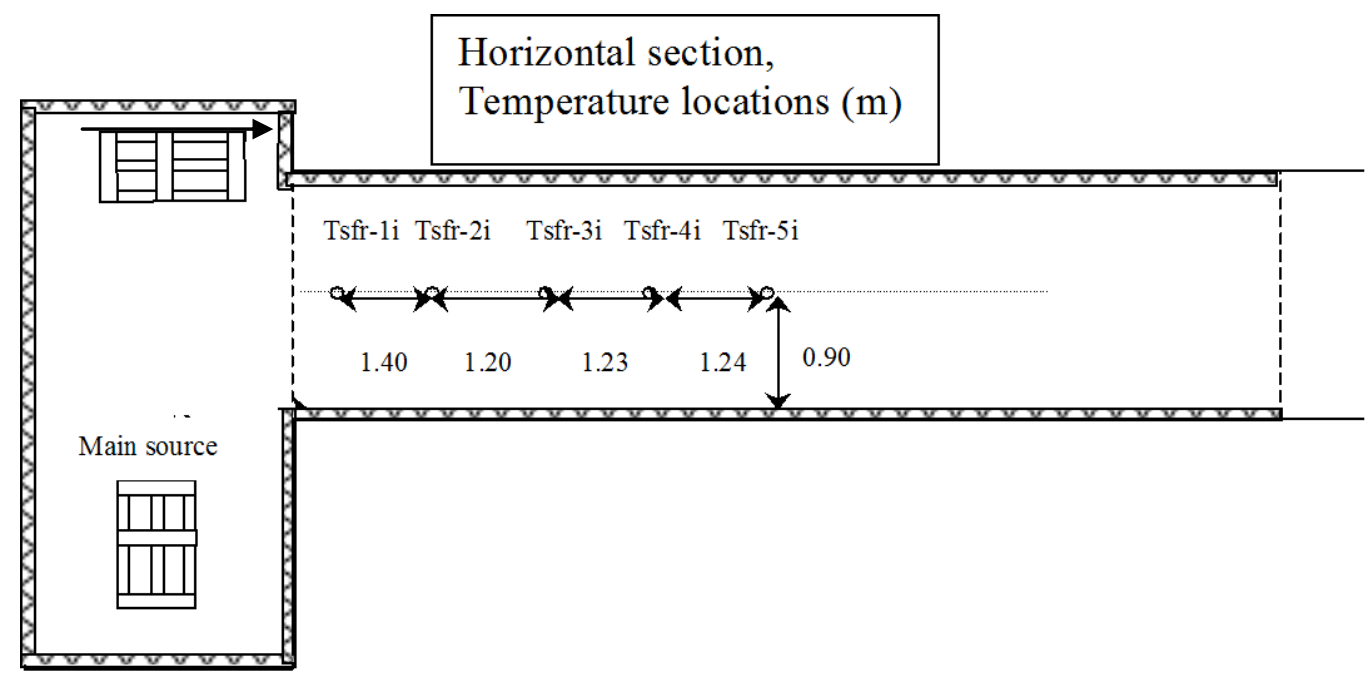

Fig. 3. Plan view of the thermocouple locations, horizontal section (distances in $\mathrm{m}$ ).

Each wood stack has been installed on a load cell in order to measure the mass loss rate of the sources during test. Measurements of oxygen and temperature have been performed in the smoke flow at the exit door using a probe and a gas analyzer (Test 350$)$. 


\section{AN UNDER-VENTILATED SCENARIO: FIRE GROWTH AND SMOKE SPREAD}

\section{Wood Pallet Stack Ignition}

Figure 4 shows the flame growth inside the main pallet stack $60 \mathrm{~s}$ and $210 \mathrm{~s}$ after ignition. It has been obtained with a webcam put inside the fire room, close to the target source and looking at the main source. $60 \mathrm{~s}$ after ignition, the flame is more important on the left size, where the fire was ignited, at a location shown by the white mark. The picture on the right illustrates the flame growth after $210 \mathrm{~s}$, a layer of smoke has filled the fire room except inside a zone of small depth close to the ground. At the same time, large amount of smokes has begun to spread inside the smoke filling space and to leave the test rig through the exit door.

\section{Fire Growth and Smoke Spread inside the Test Rig}

Before $250 \mathrm{~s}$, the heat release rate increases strongly. However after $250 \mathrm{~s}$, a large amount of smoke is present in the smoke filling rooms, which leaves a small space close to the ground available for the incoming fresh air. So the ventilation of the fire room decreases. As a feedback, the pyrolysis and the mass loss of the wood stacks are reduced and they become less intense compared to the case where the fire room would be well-ventilated. It is important to notice that no external flames were observed at the exit door during the test, meaning that no combustible gas was available in the smoke at the exit in order to produce re-ignitions by mixing with fresh air.

Temperatures inside the smoke filling space are reported in Fig. 5. They increase continuously until $1700 \mathrm{~s}$. Near the ground $(1 \mathrm{~m})$ below the ceiling $(4 \mathrm{~m})$, no significant variations between the different measuring points are observed, which reminds us that there is a stratification of smoke at these heights. However at mid-heights ( 2 and $2.5 \mathrm{~m}$ ), temperatures close to the opening between the fire room and the smoke filling space, Tsfs-14 and Tsfs-15, are much higher than the one observed farther towards the exit, Tsfs-44 or Tsfs-54, and Tsfs-45 or Tsfs-55. That suggests the flame inside the fire room is spreading a little through the opening between the two rooms.
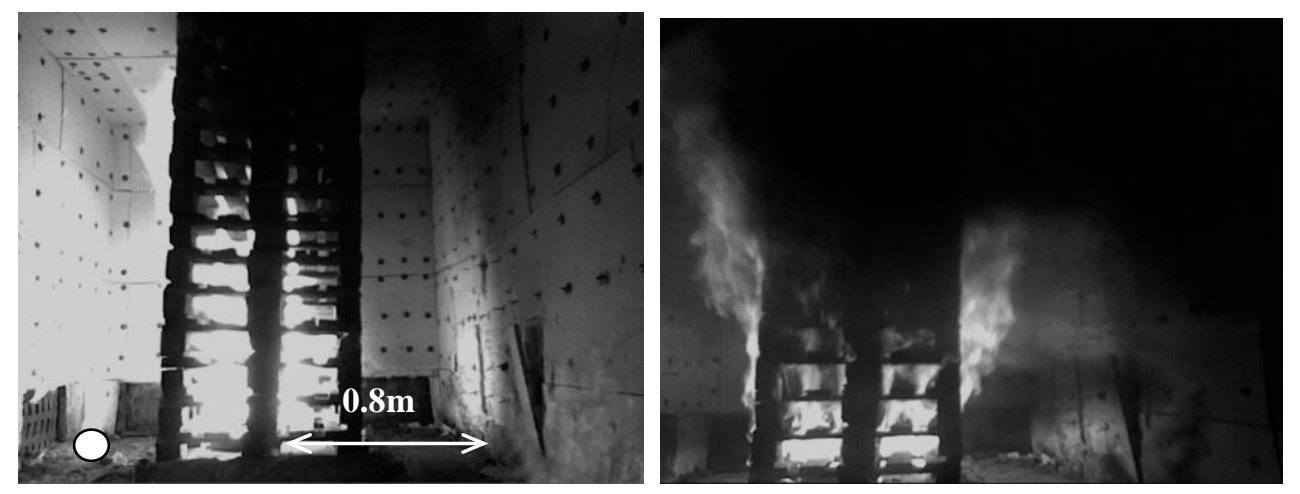

Fig. 4. Left, view of the main fire source inside the fire room $60 \mathrm{~s}$ after ignition; right, same view $210 \mathrm{~s}$ after ignition. The white circle shows the ignition location inside the wood pallet stack.

Figure 6 represents the temperature and oxygen concentration in the smoke plume at the exit door. As inside the smoke filling space, the temperature increases during the test, reaching a maximum value equal to $400{ }^{\circ} \mathrm{C}$. Values shown in Fig. 6 are lower than the ones observed in the upper zone in the smoke filling space, but very close to the ones observed just above ground (at $1 \mathrm{~m}$ ). During the first period, oxygen concentration decreases continuously until $250 \mathrm{~s}$. After, it remains very low in the exit plume. A slight increase can be observed but the average value remains close to $4 \%$ (the lack of data between $600 \mathrm{~s}$ and $900 \mathrm{~s}$ was due to an analyzer stopping during this period). So after $250 \mathrm{~s}$, the low value of the oxygen concentration in the exit plume indicates that the fire is in the under-ventilated regime. It is not possible to define an absolute threshold for the $\mathrm{O}_{2}$ concentration in the exit smoke, which could be used to determine the combustion regime (well- or under-ventilated). It depends on both compartment volume and heat release rate (HRR). As it will be shown below, a global equivalence ratio can be defined and it is more accurate to determine the fire regime. However, a value of $\mathrm{O}_{2}$ concentration about $5 \%$ has already been 
observed in other studies dealing with under-ventilated fires, in a large [5], medium [6] and small [7] scale tests.
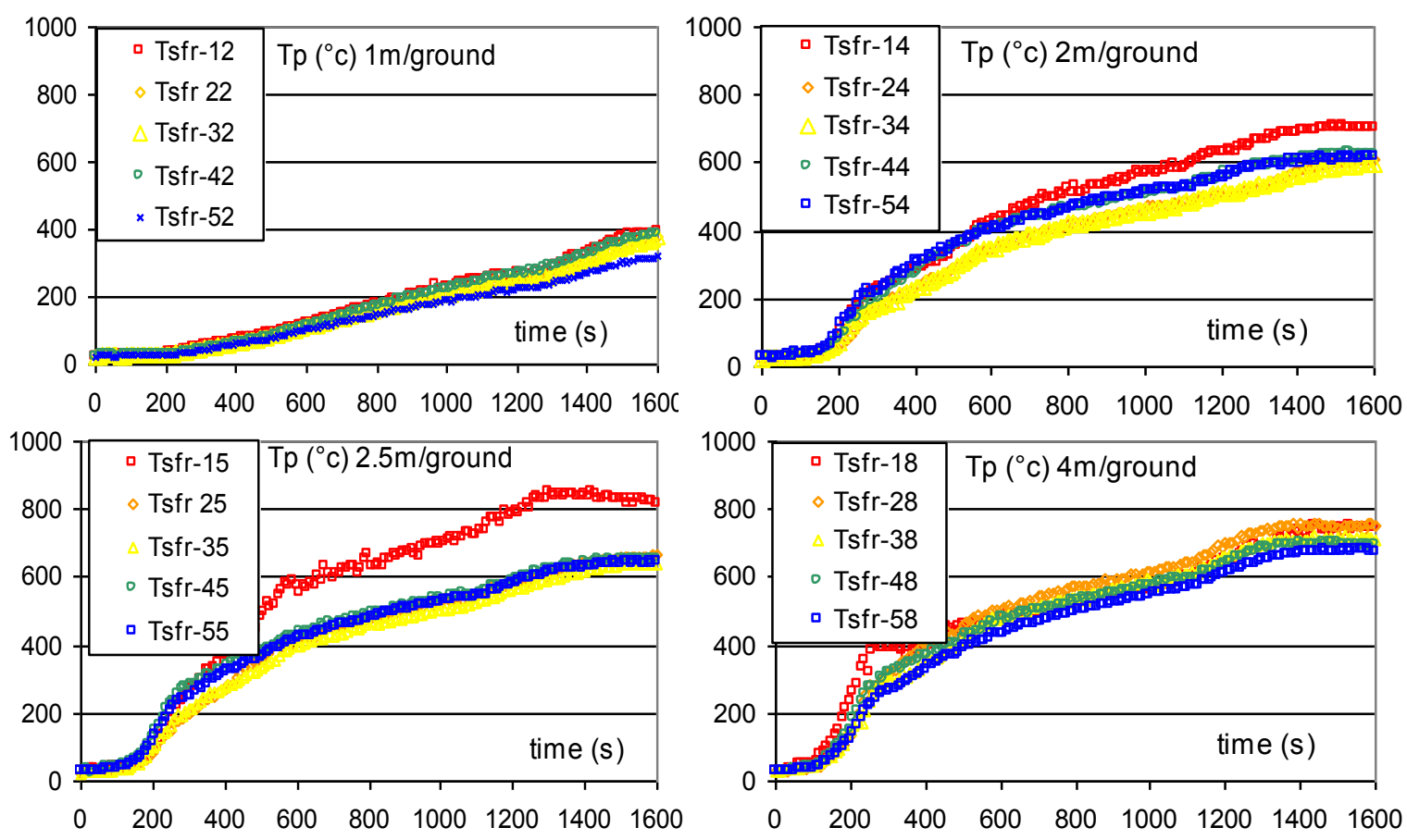

Fig. 5. Temperatures Tsfs-ji inside the smoke filling space at four heights above ground where $j$ is the thermocouple tree number and $i$ is the height number as shown in Fig. 3.

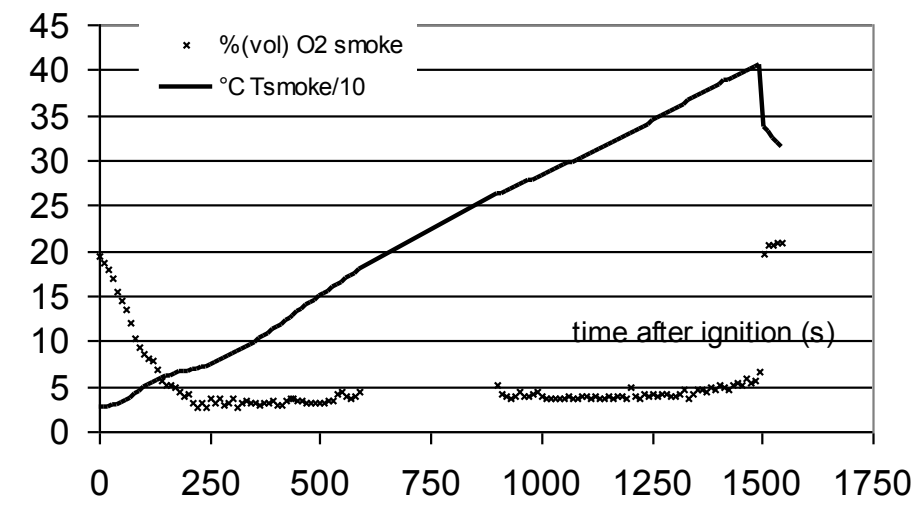

Fig. 6. Temperature and oxygen concentration in the smoke plume at the exit door.

\section{The Mass Loss Rate}

As explained previously, the mass loss rate (MLR in $\mathrm{kg} / \mathrm{s}$ ) have been determined from load cell measurements and the results are reported in Fig. 7. Some temporal sequences are important to note. Figure 4 indicates that the flame spread across the main pallet pile has occurred $250 \mathrm{~s}$ after ignition. This time corresponds to the oxygen depletion in the fire room and the beginning of the under-ventilated regime. After that, Fig. 6 shows that the total MLR continued to increase until it reaches a maximum value, $620 \mathrm{~s}$ after ignition. At this time, the MLR value of the main stack is not maximum, which has occurred at $450 \mathrm{~s}$, just after the ignition of the second source (at $300 \mathrm{~s}$ ). Finally after $620 \mathrm{~s}$, the total mass loss rate has decreased, while the temperature inside the test rig has continued to increase as shown in Fig. 5. Why the 
MLR value decreases with increasing value of temperature inside the rooms? No clear explanation has been found to understand this fire behavior.

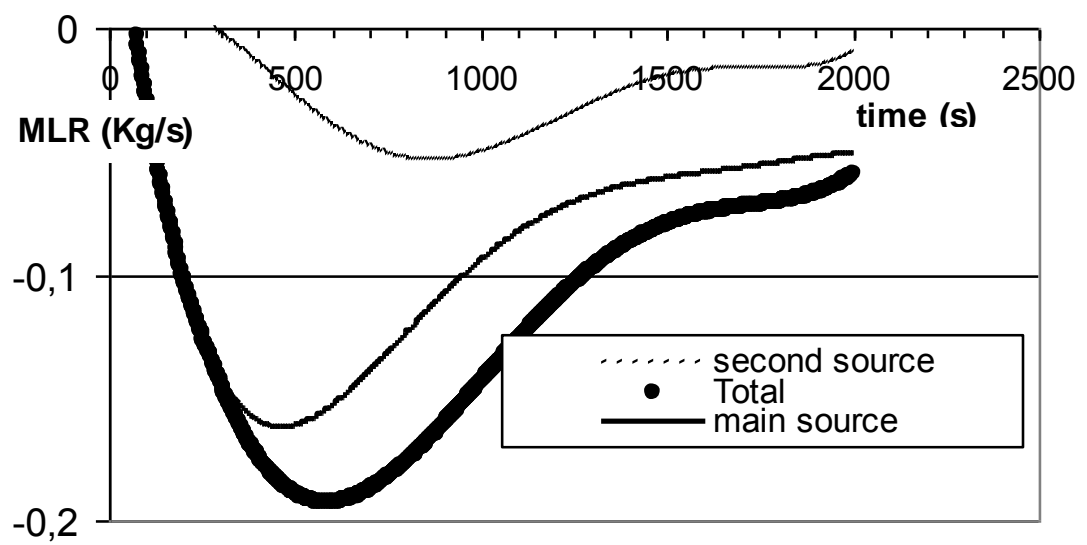

Fig. 7. Values of the mass loss rate for the main and second sources and total.

\section{HEAT RELEASE RATE CALCULATIONS}

In order to calculate the fire growth inside the different compartments, we have used FDS v5.5 [8]. With this version, it is possible to specify the rate of heat release or to use a reaction scheme for the pyrolysis. This computer code has been widely used for engineering applications, it is well documented and it has already been validated for a certain number of fire scenarios. However up to now, the under-ventilated cases have not been so much examined. This model can deal with such fire scenarios since it allows a dilution of the fuel gas with other compounds. Recently, a validation of this model, which uses a two-step combustion scheme, has been performed with data obtained on a reduced-scale ventilation-limited test $[9,10]$. However, the comparison with experimental data obtained at large scale is also an important step.

The geometry of a wood pallet stack is complicated. The surface of wood exposed to convective or radiative heat fluxes is much larger than the surface of the stack envelope, and the flame can spread inside the stack. Very fine meshes, with a size less than a few millimeters, should have to be taken to adequately describe this complex geometry of the fire source. Even if this goal is achieved, the simulations of fire growth inside the stack are significantly sensitive to material thermal and ignition properties [11]. Due to the limitations of current processors, the mesh size was taken to be $5 \mathrm{~cm}$ and uniform within the calculated domain. Thus, it was not possible to describe the exact geometry inside the stack. We have chosen to use a simplified geometry corresponding to a small compact block, with half of the real height of the stack. This corresponds a surface equal to the eighth of the real surface of wood and to about half the surface envelope.

The main difficulty of the calculation is the prediction of HRR. Two strategies have been scrutinized.

First method: A pyrolysis model with one reaction step has been used. While FDS v5.5 allows the use of a multiple reaction scheme for pyrolysis, we have chosen only one step for sake of simplicity. For real wood products, the kinetic parameters and all of the necessary properties are not well known [11], and the present scenario is too complicated and it is not suitable for analyzing these mechanisms with multiple reactions. So, it has been assumed that the mass loss rate is given by an Arrhenius law (see Ref. [8] for more details),

$\dot{m}=A Y^{n} \exp \left(-\frac{E}{R T p}\right), \quad \mathrm{Y}=\rho / \rho_{0}$

where $\rho$ is the density of the material, $\rho_{0}$ the initial value, $E$ the activation energy, $A$ the pre-exponential factor and $n$ the order of the reaction. For this study, the typical value $n=1$ has been chosen (first order reaction). The activation energy $(E)$ and pre-exponential factor $(A)$ are difficult to determine. Due to the exponential in the relation above, the pyrolysis rate increases sharply in a narrow temperature range, and it is not very sensible to the value of $A$. With $E=1.6 \times 10^{5}(\mathrm{~kJ} / \mathrm{kmol})$, this abrupt variation occurs around $250^{\circ} \mathrm{C}$, which is representative of the ignition temperature of wood. For $A$, two different values have been 
tested, $A l=7.5 \times 10^{11}$ and $A 2=1.1 \times 10^{12}$. In the following, the calculated results obtained with these $A$ values will be called PYRO_E_A1 and PYRO_E_A2. A heat of vaporization for the fuel $(300 \mathrm{~kJ} / \mathrm{kg})$ has been used.

Second method: The solid fuel has released the fuel gases at a specified rate. It needs to specify a time evolution of the heat release rate per unit area (HRRPUA) for a given surface of the fire source. Some typical values of HRR for several wood pallet fires are given in Ref. [12], and they have been interpolated in order to determine the HRRmax value for the size of the pallets used in the present study. We have found HRRmax equal to 3.2 MW for the main source. For the growth of the fire, a time-square law has been taken with an alpha coefficient equal to $0.02 \mathrm{~kW} / \mathrm{s}^{2}$ (corresponding to a Medium growth). With these values, flames have been predicted at the exit door while they were never observed, and the calculated temperature inside the smoke filling space was too high, as it will be shown below. Thus it has been considered that the above values of HRRmax and alpha correspond to a well-ventilated fire source and that, in the underventilated case, they have to be reduced. So, several calculations were made by decreasing the previous settings until there are no external flames at the exit door and there is a good agreement between calculated and measured values of temperature inside the smoke filling space. The limit has been found equal to $0.650 \mathrm{MW}$ for HRRmax and $0.01 \mathrm{~kW} / \mathrm{s}^{2}$ for alpha, allowing to burn all the combustible inside the compartment. The results given by these sets of parameters will be called HRR_SPEC and HRR_SPEC_R $(\mathrm{R}=$ reduced $)$.

The previous calculations HRR_SPEC and HRR_SPEC_R do not take into account of the pyrolysis process, which controls the heat release in the fire room. The mass loss rate MLR has been measured in the present study. In well-ventilated fires, the law HRR $=$ MLR $\times$ Hcomb is applicable. We applied it, which has corresponded to a fire scenario with HRRmax equal to $2.8 \mathrm{MW}$ and occurring at $610 \mathrm{~s}$, the time at which MLR value is maximum as shown in Fig. 7. With this specified HHR, external flames have been also predicted at the exit door. However, for comparison with previous results, they are also presented and they will be called HRR_MLR.

For all calculations, a net heat of combustion of $14 \mathrm{MJ} / \mathrm{kg}$ in the gas phase is taken, which is less than that recommended by Parker [13].

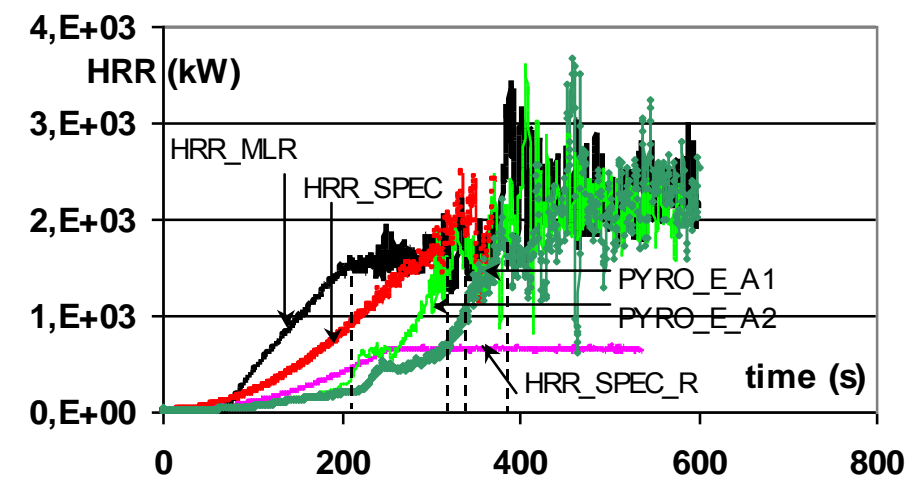

Fig. 8. Total heat release rate (HRR) inside the test rig and calculated using different methods. Dotted lines indicate for each method the transition to the under-ventilated regime.

\section{RESULTS AND DISCUSSIONS}

\section{Heat Release Rate}

Figure 8 shows the total HRR values inside the test rig, and calculated with the different methods described above. Up to $150 \mathrm{~s}$, the fire growth is much faster for the cases HRR_SPEC and HRR_MLR compared to the PYRO_E_A cases. These provide a strong growth of HRR after $200 \mathrm{~s}$ until it reaches the values provided by the methods with specified HRR. As expected, this sharp growth occurs at a shorter time if the pre-exponential factor is bigger. For all cases, a first plateau is reached at around $1.6 \times 10^{3} \mathrm{~kW}$, but at different times, as indicated by the dotted lines in Fig. 8. The plateau is reached more quickly, about $200 \mathrm{~s}$ 
after ignition, for the HRR_MLR case, and later, at about 350 s, for the PYRO_A1 case. For each scenario, this time corresponds to a change in the fire ventilation regime. Before, there is enough oxygen in the fire room for the combustion, and the fire is well ventilated. After oxygen depletion occurs in the fire room and the fire becomes under-ventilated. This is confirmed by the change of $\mathrm{O}_{2}$ concentration in the smoke at the exit as shown in Fig. 6, where a transition is observed at $250 \mathrm{~s}$. The global equivalence ratio can be used to characterize the ventilation conditions $[14,15]$ :

$$
G E R=s \dot{m}_{f} / \dot{m}_{a} Y_{o 2, a}
$$

where $s$ is the oxygen-fuel stoichiometric ratio for the complete reaction, it is determined from the elemental composition of wood used in this study, $\mathrm{C}=3.4, \mathrm{H}=6.2, \mathrm{O}=2.5 . Y_{O 2, a}$ is the oxygen mass fraction in ambient air, $m_{f}$ and $m_{a}$ represent respectively the fuel flow rate and air inflow rate. This last one has not been measured, and we have used the values provided by calculations. At $250 \mathrm{~s}$, we found with the calculations PYRO_A1 and HRR_SPEC_R, GER= 11.5 and 3.15 respectively. Even if these GER results are different, the values are well greater than one, indicating that the fire is under-ventilated.

Harmathy [16] (see also Drysdale [17]) has gathered a multitude of experimental data on the combustion of wood cribs in compartments. He identified the transition point between ventilation-controlled and fuelcontrolled regime at $\Phi / A_{f}=0.263$, $\Phi$ being the ventilation parameter and given by $\Phi=3.77 A_{w} \sqrt{ } H\left(A_{w}\right.$ is the opening surface and $H$ its height) and $A_{f}$ the free surface of the wood (exposed and available for pyrolysis). In the present work, $\Phi=7.76$ and $A_{f}=33 \mathrm{~m}^{2}$, we find $\Phi / A_{f}=0.235$ corresponding to the underventilated regime. In that case, Harmathy has proposed the relation MLR $=0.236 \Phi$, which gives MLR $=0.183 \mathrm{~kg} / \mathrm{s}$. This last value is very close the maximum value observed in Fig. 7 .

After this short plateau, the heat release increases again due to ignition of target pallets (the second source). This time is given by all methods at about $350 \mathrm{~s}$, which is close to the observation as shown in Fig. 7. In Fig. 8 calculations show strong fluctuations after $350 \mathrm{~s}$. They are due to the gas combustion which does not occur close to the wood pallets but mainly in the smoke filling space, and this brings large instabilities in the fluid inside this space. The locations of zones of heat release rate are not stable and their position fluctuates from the fire room to the exit.

\section{Temperatures}

Figure 9 shows temperatures calculated and measured inside the smoke filling space at the four heights above ground. For each height, the measured temperatures (see Fig. 3) are presented separately for the first tree close to the fire room (Tsfs-1i) and for the average on the trees furthest away from the fire room (Tsfs$\mathrm{ji}, j=2$ to 5 ). The calculated results correspond to the average on a horizontal plan.

With HRR_SPEC and HRR_MLR, there is an overestimation of the temperature for all the times. The prediction of the fire growth is too fast. Another important difference with the observations is found near the ground. As seen in Fig. 9, a layer of hot smoke $(900-1000 \mathrm{~K})$ is predicted at $1 \mathrm{~m}$ above the ground, which is far from reality. With pyrolysis models, the agreement is better at the beginning of the fire, until time is equal to $250 \mathrm{~s}$. For all cases, excepted for HRR_SPEC_R, a plateau, already shown with the previous results on HRR, is observed and it corresponds to about $800 \mathrm{~K}$ at 2.5 and $4 \mathrm{~m}$ above ground (level 5 and 8 on the thermocouple trees). This time corresponds to a change in the fire ventilation regime, however this transition is not so pronounced on the measured temperature profiles. After this plateau, the second source ignites and the temperatures increase again quickly, to then reach a more or less stable and high value (900 K or more).

During this last period, such high temperatures show that the combustion in the gas phase is performed in the smoke filling space, which is not the reality. As shown by the measurements on Figs. 5 or 9 , the flame inside the fire room is spreading a little outside through its opening, but not in all the smoke filling space. During the test, it was possible to have a visual inspection of the fire throughout the exit door, it showed that the main zone of flames was inside the fire room and not distributed inside the smoke filling space. In the fire room, a large recirculation has been observed going from the main source towards the target and filling all the space inside this compartment, this has suggested that the air which fed the wood pallets was 
strongly diluted and vitiated by the combustion gases. Such a combustion regime may not be well reproduced by the combustion model used in FDS v5 for the gas phase, although with this release, the dilution of combustible gases by other compounds is permitted.

In Fig. 9, the temperatures calculated with the pyrolysis of the main source show a fast increase between 300 and $400 \mathrm{~s}$, and such a variation occurs also but later for the second source. This is not observed on measures. As previously noted, this is due to the exponential factor in the Arrhenius's law, the pyrolysis rate increases sharply in a narrow temperature range. With the value of $E$ equal to $1.6 \times 10^{5} \mathrm{~kJ} / \mathrm{kmol}$, this abrupt variation occurs around $250{ }^{\circ} \mathrm{C}$. The sensibility of the calculated results, HRR or $T p$, to the $E$ value is strong. A decrease of a few percent can provide an extinction of the fire. This sensibility is one weakness of the pyrolysis mechanism with one step. With a multi-step mechanism, some reactions may have a kinetic which can act as a limiting step, which can improve the calculations.

One might suspect to obtain better results (less than overestimated), if the formation of char is taken into account in the process of pyrolysis. Several trials were performed using values of char parameters close to the standard ones (conductivity $=0.077 \mathrm{~W} / \mathrm{m} \cdot \mathrm{K}$, heat capacity $=0.68 \mathrm{~kJ} / \mathrm{kg} \cdot \mathrm{K}$ ). The attenuation of the heat flow, caused by the char layer, is too strong and the complete extinction occurs. More reliable values of the char parameters have to be found in order to obtain better results.

With the pyrolysis approach used in this study, another simplification is the effective surface that has been used to represent the fire source, and equal to the eighth of the real surface of wood pieces and to about half the surface envelope. With the method with specified HRR, the value of this surface has not a strong influence, since this is the HRR value that is specified in the gas phase. With the pyrolysis, the choice of this surface also influences the value taken for the kinetic parameters. A too small surface will lead to kinetic parameters allowing a stronger pyrolysis process and vice versa. This artifact is due to the coarse mesh used $(5 \mathrm{~cm})$ and which does not resolve the complex geometry inside the pallet stack. As it is highlight in the FDS validation guide [11], "the grid sensitivity and uncertain material properties make blind predictions of fire growth on real materials beyond the reach of the current version of the model. However, the model can still be used for a qualitative assessment of fire behavior as long as the uncertainty in the flame spread rate is recognized". For situations in which the heat release rate is calculated with a pyrolysis model and in which the combustible cannot be resolved by the mesh size, one would like to know which effective surface has to be taken as a function of the geometry of the fire source. Further studies are necessary to look at this issue.

Finally, the best results have been obtained by choosing a reduced value of HRR (HRR_SPEC_R case). In this scenario and for the main source, HRRmax and alpha have been taken equal to 0.650 MW and $0.01 \mathrm{~kW} / \mathrm{s}^{2}$ respectively. So it has been necessary to reduce the HRRmax value of the HRR-SPEC scenario from 3.2 to $0.65 \mathrm{MW}$ in order to have a good agreement between calculated and measured temperatures inside the smoke filling space. The same comment also applies for the HRR_MLR case which has given a maximum value of HRR equal to $2.8 \mathrm{MW}$, as explained above. If we compare these two scenarios, HRR_SPEC and HRR_MLR, to HRR_SPEC_R which is the best scenario, the heat release rate of the source in the well-ventilated regime has to be reduced by one-fifth or one-quarter in order to have accurate temperatures calculated for the under-ventilated regime.

\section{CONCLUSION}

The full-scale test carried out has allowed the study of the growth of an under-ventilated fire of wood pallets. The test rig consists of a fire room and a smoke filling space, the latter is connected at the opposite side to an exit door. Temperatures observed in these compartments show the fire has increased in a short time (about $200 \mathrm{~s}$ ), consuming a large amount of oxygen available in the fire room, and leading to an under-ventilated combustion regime in this room. The main flame zone was inside the fire room and it was spreading a little through the opening between the two rooms, but not in all the smoke filling space.

The calculation of the fire growth has been carried out with FDS v5.5 using different methods to determine the heat release rate HRR, this one has been specified or calculated by taking into account the pyrolysis process with one Arrhenius's law. All the methods reproduce quite well the sequence of events, fire growth, transition to the under-ventilated regime and ignition of the secondary source. Associated times are also fairly well predicted. 
The comparison of calculated and measured temperatures inside the smoke filling space shows that the calculated heat release rate is over-estimated. When the HRR is specified, two sets of input values were determined from available data corresponding to well-ventilated cases. This has provided too high temperature values and the heat release mainly located inside the smoke filling space, which was not the reality. The HRRmax has to be reduced by one-fifth or one-quarter, depending of the method used to specify the HHR, in order to obtain better results of temperature. For the pyrolysis approach, the agreement is good at the beginning of the fire, however the pyrolysed mass flux increases too much when a temperature threshold is reached, implying too big HRR values and an overestimation of temperatures. The use of a mechanism with several steps should improve the calculations.
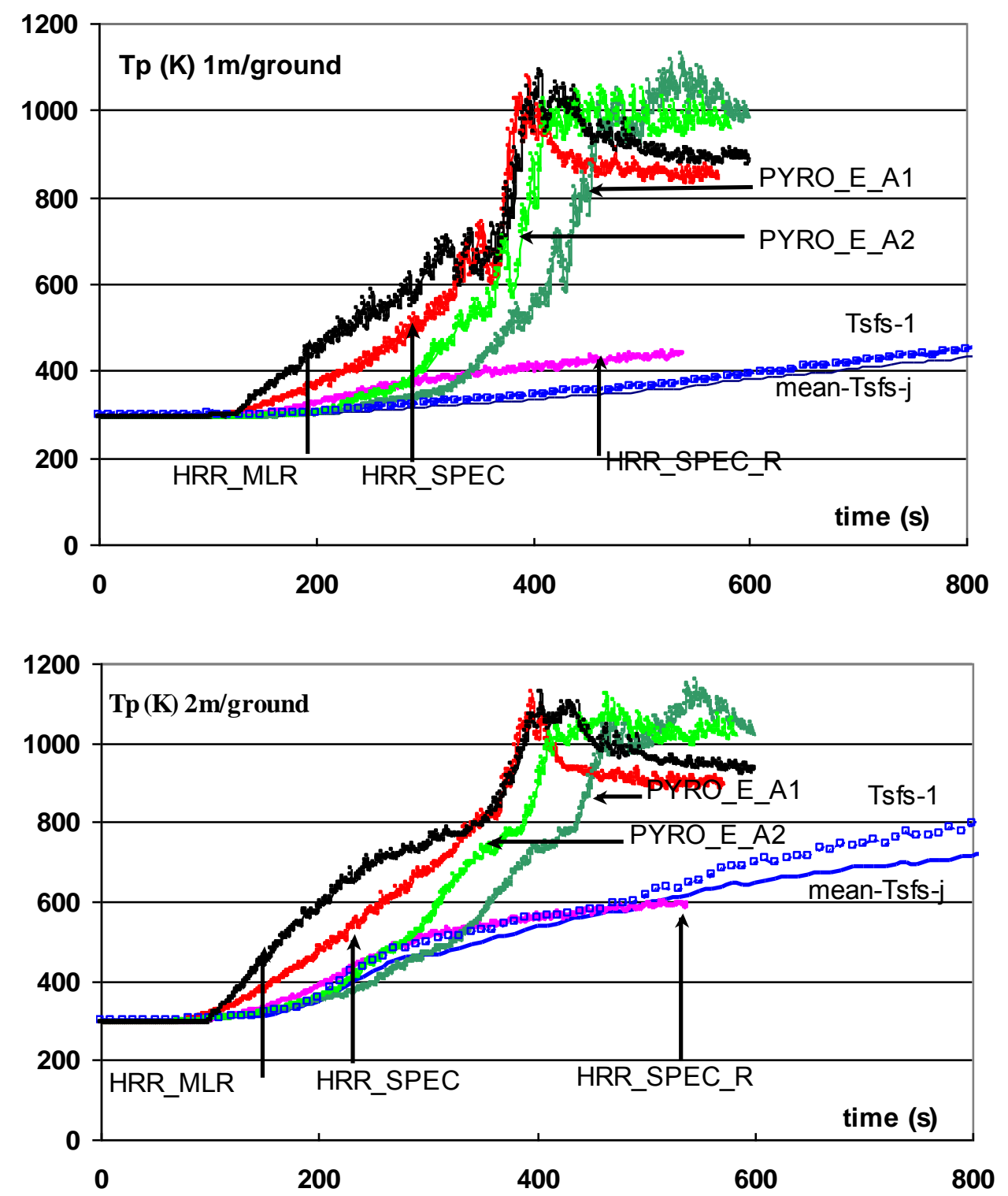

Fig. 9. Comparison between measured and calculated temperatures in the smoke filling space at different planes above ground, mean Tsfs-j is the average value over the $j=2$ to 5 thermocouple trees, Tsfs 1 is the temperature at the first tree close to the fire room as detailed in Fig. 3 

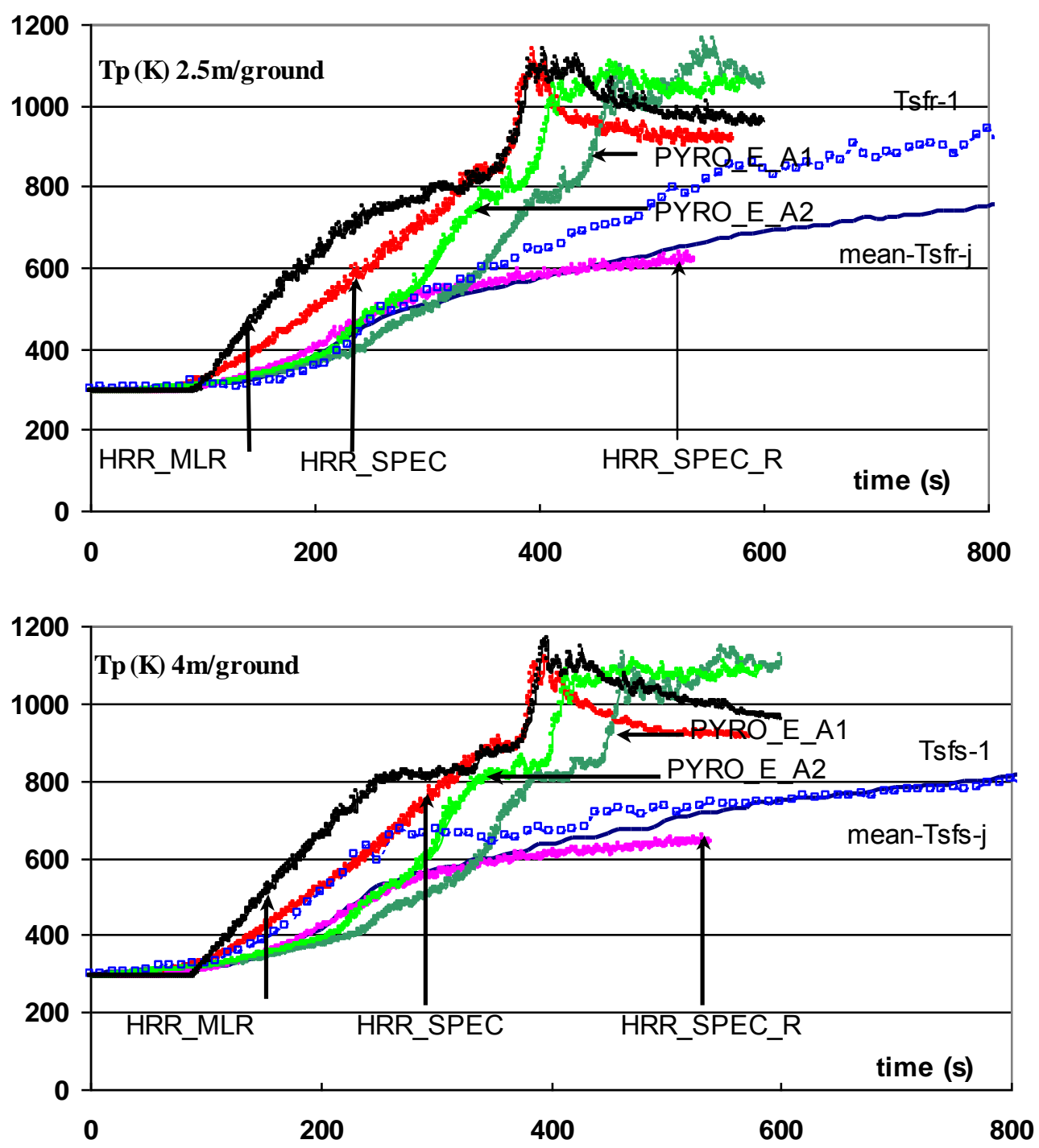

Fig. 9. (continued). Comparison between measured and calculated temperatures in the smoke filling space at different planes above ground, mean Tsfs-j is the average value over the $j=2$ to 5 thermocouple trees, Tsfs 1 is the temperature at the first tree close to the fire room as detailed in Fig. 3.

\section{ACKNOWLEDGMENTS}

The fire test has been performed and financed by the PROMESIS consortium in September 2008 using the SERAFIN research station (located at Roanne, France). PROMESIS has close to 18 partners on a research program dedicated to the comparative study of the means and the methods for firefighting.

\section{REFERENCES}

[1] McGrattan, K., Hamins, A., Hostikka, S., Floyd, J., Klein, B., "Fire Dynamics Simulator (Version 5) Verification \& Validation Guide Volume 1: Verification" NIST Special Publication 2007.

[2] McGrattan, K.B., "Verification and Validation of Selected Fire Models for Nuclear Power Plant Applications." Volume 7. Fire Dynamics Simulator (FDS). NUREG-1824; EPRI 1011999; Volume 7; May 2007, 205 p. 
[3] Stekler, K., Quintiere, J.G., Rinkinen, W., "Flow induced by fire in a compartment" NBSIR 822520, 1982.

[4] Abecassis-Empis, C., Reszka, P., Steinhaus, T., Cowlard, A., Biteau, H., Welch, S., Rein, G., Torero J.L., (2008) "Characterisation of Dalmarnock fire Test One", Experimental Thermal and Fluid Science 32: 1334-1343, http://dx.doi.org/10.1016/j.expthermflusci.2007.11.006

[5] Lock, A., Bundy, M., Johnsson, E., Hamins, A., Ko, G., Hwang, C., Fuss, P., Harris, R., "Experimental Study of the Effects of Fuel Type, Fuel Distribution, and Vent Size on Full-Scale Underventilated Compartment Fires in an ISO 9705 Room", NIST Technical Note 1603, 2008.

[6] Sugawa, O., Kawagoe, K., Ok, Y., Ogara, I., (1989) "Burning behavior in a poorly-ventilated compartment fire", Fire Science \& Technology, 9: 5-14. http://dx.doi.org/10.3210/fst.9.2_5

[7] Utiskul, Y., Quintiere, J.G., Rangwala, A.S., Ringwelski, B.A., Wakatsuki, K., Naruse, T., (2005) "Compartment fire phenomena under limited Ventilation", Fire Safety Journal 40:367-390, http://dx.doi.org/10.1016/j.firesaf.2005.02.002

[8] McGrattan, K., "Fire Dynamics Simulator (Version 5) Technical Reference Guide", NIST Special Publication 1018-5, 2007

[9] Floyd, J. and Mcgrattan, K.B., 2009. Validation of a CFD Fire Model Using Two Step Combustion Chemistry using the NIST Reduced-scale Ventilation-limited Compartment Data. Fire Safety Science 9: 117-128. http://dx.doi.org/10.3801/IAFSS.FSS.9-117

[10] Floyd, J.E., McGrattan, K., (2009) Extending the mixture fraction concept to address underventilated fires", Fire Safety Journal 44(3): 291-300, http://dx.doi.org/10.1016/j.firesaf.2008.07.002

[11] McGrattan, K., Hostikka, S., Floyd, J., McDermott, R. Fire Dynamics Simulator (Version 5) Technical Reference Guide Volume 3: Validation, NIST Special Publication 1018-5, Gaithersburg, MD, 2010.

[12] Babrauskas V., "Burning Rates", The SFPE Handbook of Fire Protection Engineering Engineering, $\left(2^{\text {nd }}\right.$ ed.)., National Fire Protection Association, Massachusetts, P.J. DiNenno et al. (Eds.), USA, 3-1-3-15, 2002.

[13] Parker, J., "Calculation of the heat release rate by oxygen consumption for various applications", NBSIR 81-2427-1, 1982.

[14] Gottuk, D. Lattimer, B., "Effect of combustion conditions on species production", The SFPE Handbook of Fire Protection Engineering, ( $2^{\text {nd }}$ ed.)., National Fire Protection Association, Massachusetts, P.J. DiNenno et al. (Eds.), USA, , 2002, 3-1-3-15

[15] Pitts, W.M., (1995), The global equivalence ratio concept and formation mechanisms of carbon monoxide in enclosure fires, Progress in Energy and Combustion Science, 21:197-237. http://dx.doi.org/10.1016/0360-1285(95)00004-2

[16] Harmathy, T.Z. (1972), “A New Look at Compartment Fires, Part I”, Fire Technology, 8, 196219. http://dx.doi.org/10.1007/BF02590544

[17] Drysdale, D., An Introduction to Fire Dynamics, John Wiley and Sons, Chichester, 1985. 